\title{
Regulatory role of PBAN in sex pheromone biosynthesis of heliothine moths
}

\author{
Russell Jurenka ${ }^{1}$ and Ada Rafaeli ${ }^{2}$ \\ 1 Department of Entomology, lowa State University, Ames, IA, USA \\ ${ }^{2}$ Department of Food Quality and Safety, Volcani Center, Agricultural Research Organization, Bet Dagan, Israel
}

\section{Edited by:}

Joe Hull, United States Department of Agriculture, USA

\section{Reviewed by:}

Taisen Iguchi, National Institute for Basic Biology, Japan

Sergio Polakof, French National Institute for Agricultural Research, France

Miriam Altstein, Agricultural Research Organization, Israel

*Correspondence:

Russell Jurenka, Department of Entomology, lowa State University,

Ames, IA 50011-3222, USA.

e-mail: rjurenka@iastate.edu
Both males and females of heliothine moths utilize sex-pheromones during the mating process. Females produce and release a sex pheromone for the long-range attraction of males for mating. Production of sex pheromone in females is controlled by the peptide hormone (pheromone biosynthesis activating neuropeptide, PBAN). This review will highlight what is known about the role PBAN plays in controlling pheromone production in female moths. Male moths produce compounds associated with a hairpencil structure associated with the aedaegus that are used as short-range aphrodisiacs during the mating process. We will discuss the role that PBAN plays in regulating male production of hairpencil pheromones.

Keywords: pheromone, PBAN, Heliothis, Helicoverpa, moth

\section{BACKGROUND ON PBAN}

The hormonal regulation of pheromone biosynthesis in moths was first demonstrated in the heliothine Helicoverpa zea (Raina et al., 1987) and a peptide isolated shortly thereafter (Raina et al., 1989). Pheromone biosynthesis activating neuropeptide (PBAN) was identified as a 33 amino acid $C$-terminal amidated peptide from the brain-subesophageal ganglion complex of adult female moths. Immunohistochemical procedures traced the neuronal production of PBAN to three groups of neurons in the subesophageal ganglion (Blackburn et al., 1992; Kingan et al., 1992; Rafaeli and Jurenka, 2003). The gene encoding for PBAN was subsequently identified (Davis et al., 1992; Ma et al., 1994, 1998). In addition to encoding for PBAN four other neuropeptides could be produced. One of these had been identified as the diapause hormone that regulates embryonic diapause in the silkworm moth (Imai et al., 1991). The analysis of mRNA from a number of moth species now indicates that five peptides could be produced by the PBAN gene (Choi et al., 2004). Evidence indicates that these peptides could be processed and released into circulation as active neuropeptides (Ma et al., 1996).

Sequence similarities to the pyrokinins became evident after it was determined that the minimum activity required was the last five $C$-terminal amino acids (Raina and Kempe, 1990, 1992). Leukopyrokinin was first identified in the cockroach Leucophaea maderae due to the stimulation of hindgut muscle contraction (Holman et al., 1986). A variety of PBAN/pyrokinin peptides have been found in all insects to date based on gene sequence and peptide isolation (Jurenka and Nusawardani, 2011). These peptides are found in neurons localized to the brain-subesophageal ganglion and ganglia of the ventral nerve cord. Most insects possess another peptide produced by the capa gene. This gene, first identified in Drosophila melanogaster (Kean et al., 2002), can produce three peptides. Two of the peptides are periviscerokinins that usually have an FPRVamide $C$-terminal ending. Periviscerokinins are involved in a variety of functions including stimulating heart rate and affecting Malpighian tubule functions. The third peptide, that can be produced by the capa gene, is related to the diapause hormone because it has a WFGPRLamide $C$-terminal ending.

As indicated above the first functions described for the PBAN/pyrokinin family of peptides was stimulation of pheromone biosynthesis in female moths and stimulation of hindgut muscle contraction in cockroaches. Other functions were soon described for peptides in the family including induction of embryonic diapause in females and cuticle melanization in larvae of the silkworm moth, Bombyx mori (Matsumoto et al., 1990; Imai et al., 1991). Once the peptides were identified it became apparent that these peptides belong to the same family with cross-reactivity of function. Subsequently other functions were identified including acceleration of puparium formation in higher flies (Zdarek et al., 1997) and pupal diapause development in heliothine moths (Sun et al., 2003; Zhang et al., 2004). This list of functions indicates the pleiotropic nature of the PBAN/pyrokinin family of peptides across the Insecta. Other functions could potentially be found for the family because these peptides are found in all insects (Jurenka and Nusawardani, 2011).

The target tissue for the action of PBAN in adult female moths is the pheromone gland, which is found as intersegmental tissues located between the eighth and ninth abdominal segments of the ovipositor in heliothines (Rafaeli and Jurenka, 2003). Pheromone biosynthesis can be stimulated by either injecting peptides into intact female moths or peptides can be incubated with an isolated pheromone gland on saline. The in vitro studies demonstrate that the PBAN-receptors are located in the epidermal cells of the 
pheromone gland. A biologically active biotinylated-PBAN analog was used to demonstrate specific binding to a protein from isolated pheromone glands (Rafaeli et al., 2003). Cloning and functional expression of a PBAN-receptor was first reported in H. zea, the same moth in which PBAN was first identified (Choi et al., 2003).

\section{PBAN-RECEPTOR}

The PBAN-receptor was identified based on sequence similarities with a group of three receptors from D. melanogaster. After the D. melanogaster genome was sequenced and annotated peptide G-protein coupled receptors (GPCR) were identified based on sequence alignment with known vertebrate peptide GPCRs (Hewes and Taghert, 2001). One group of three receptors (CG8784, CG8795, CG9918) had sequence similarities with the neuromedin $\mathrm{U}(\mathrm{NmU})$ receptor from mammals. The ligand, $\mathrm{NmU}$, has a $C$-terminal ending of FRPRNamide, which is similar to the $C$-terminal ending of PBAN, FSPRLamide. Choi et al. (2003) demonstrated that the vertebrate NmU peptide stimulated pheromone biosynthesis in female moths indicating crossreactivity and receptor activation. The D. melanogaster sequences were used in a PCR based sequencing approach to obtain the full-length sequence from pheromone glands of $H$. zea. The three receptors from $D$. melanogaster were also characterized as being activated by pyrokinins (Park et al., 2002) indicating that all of these receptors belong to a similar family.

The functional expression of the H. zea PBAN-receptor indicated that PBAN activated the receptor at a half-maximum effective concentration of $25 \mathrm{nM}$ (Choi et al., 2003). Several other peptides produced by the PBAN-gene were also active at similar concentrations. Although, concentrations required to stimulate pheromone biosynthesis in vitro in Helicoverpa armigera showed that PBAN was active at $0.5 \mathrm{nM}$ and the other peptides at significantly higher concentrations (Stern et al., 2007). PBAN-receptors have been characterized from several moths including $B$. mori (Hull et al., 2004), Heliothis virescens (Kim et al., 2008), and Plutella xylostella (Lee et al., 2011). These studies indicate that PBAN will activate receptors at concentrations in the low nanomolar range. Several other PBAN-receptors have been identified based on sequence homology from other moths including $H$. armigera (Rafaeli et al., 2007), Spodoptera exigua (Cheng et al., 2010), and Spodoptera littoralis (Zheng et al., 2007).

Only one PBAN-receptor sequence was identified from pheromone glands of $H$. zea (Choi et al., 2003). However, three PBAN-receptor sequences were identified from cDNA obtained from the central nervous system of $H$. virescens fourth instar larvae (Kim et al., 2008). All three receptor sequences were identical except for $C$-terminal extensions. The $\mathrm{N}$-terminal and seven-transmembrane domain regions of the $H$. virescens PBANreceptors are about $98.5 \%$ identical with the $H$. zea and $H$. armigera receptors. The $H$. virescens $\mathrm{PBAN}$-receptor subtype $\mathrm{C}$, was identified in pheromone glands of adult female $H$. virescens. The other two were identified from the larval central nervous system and did not have activity when tested in a calcium mobilization assay using a heterologous expression system (Kim et al., 2008). The $C$-terminal extension of $H$. virescens PBAN-receptor subtype $\mathrm{C}$ is similar to the $C$-terminal of the $B$. mori PBAN-receptor
(Hull et al., 2004). The $C$-terminal extension in the B. mori PBAN-receptor is involved in efficient internalization of the receptor after activation (Hull et al., 2004). It is interesting to note that the PBAN-receptors identified from pheromone glands of other moths have a shortened $C$-terminal ending similar to that of the H. zea PBAN-receptor. Functional significance of a short $C$ terminal ending indicates that the receptor could remain active in the pheromone gland cell membrane for a longer period of time. Time course studies on induction of pheromone biosynthesis in isolated pheromone glands indicated that the PBAN-receptor does remain active for a period of time after stimulation by PBAN (Choi et al., 2004).

The diapause hormone-receptor (DH-receptor) has high sequence homology to the PBAN-receptor especially in the transmembrane domains (Jurenka and Nusawardani, 2011). In Lepidoptera the $\mathrm{DH}$-receptor has only been characterized from $B$. mori (Homma et al., 2006). Other insects have a pyrokinin 1-receptor (PK1-receptor) that is similar to the DH-receptor in sequence and are activated by DH-like peptides with an FGPRLamide $C$ terminal ending. Other insects also have PK2-receptors that are similar to the PBAN-receptor. A third GPCR is the perivicerokininreceptor (PVK-receptor) that is activated by PVKs but not by other PBAN/pyrokinin-like peptides (Iversen et al., 2002; Park et al., 2002; Olsen et al., 2007). Phylogenetic relationships of these receptors from insects indicate three groups of receptors that follow a typical evolutionary origin for orders of insects (Figure 1).

G-protein coupled receptors have a seven-transmembrane domain motif that appears to be structurally conserved. With the $\mathrm{X}$-ray crystal structure of rhodopsin, $\beta_{1}$ and $\beta_{2}$ adrenergic receptors, and $\mathrm{A}_{2 \mathrm{~A}}$ adenosine receptors published, it is possible to construct homology models based on these solved three-dimensional structures. A detailed model of the H. zea PBAN-receptor was built using the crystal structure of rhodopsin as a template and in silico binding studies indicated possible interactions with PBAN as a ligand (Stern et al., 2007). A putative ligand binding pocket was indicated in a study utilizing an evolutionary trace approach in comparing the insect PBAN-receptors (Jurenka and Nusawardani, 2011). The conserved nature of the transmembrane domains and structural features of the ligand binding pocket for GPCRs allows the prediction of ligand interactions in a binding pocket of the PBAN-receptor. A model illustrating a putative H. zea PBANreceptor binding pocket is shown in Figure 2. This model will need to be verified with mutation studies to determine if the specified amino acids are involved in ligand binding.

Several mutation studies have been conducted to determine which domains of the PBAN-receptor are involved in ligand recognition and activation. One study utilized chimeras where the extracellular domains were exchanged sequentially between the $H$. zea PBAN-receptor and the D. melanogaster PK1-receptor (Choi et al., 2007). All extracellular domain chimeras reduced activity of the chimera receptor when challenged with PBAN. However the H. zea PBAN-receptor chimera with the third extracellular loop exchanged had increased activity when challenged with the diapause hormone. The D. melanogaster PK1-receptor chimera with the third extracellular loop exchanged had increased activity when challenged with PBAN. These results indicate that the third extracellular loop is important for peptide recognition and 


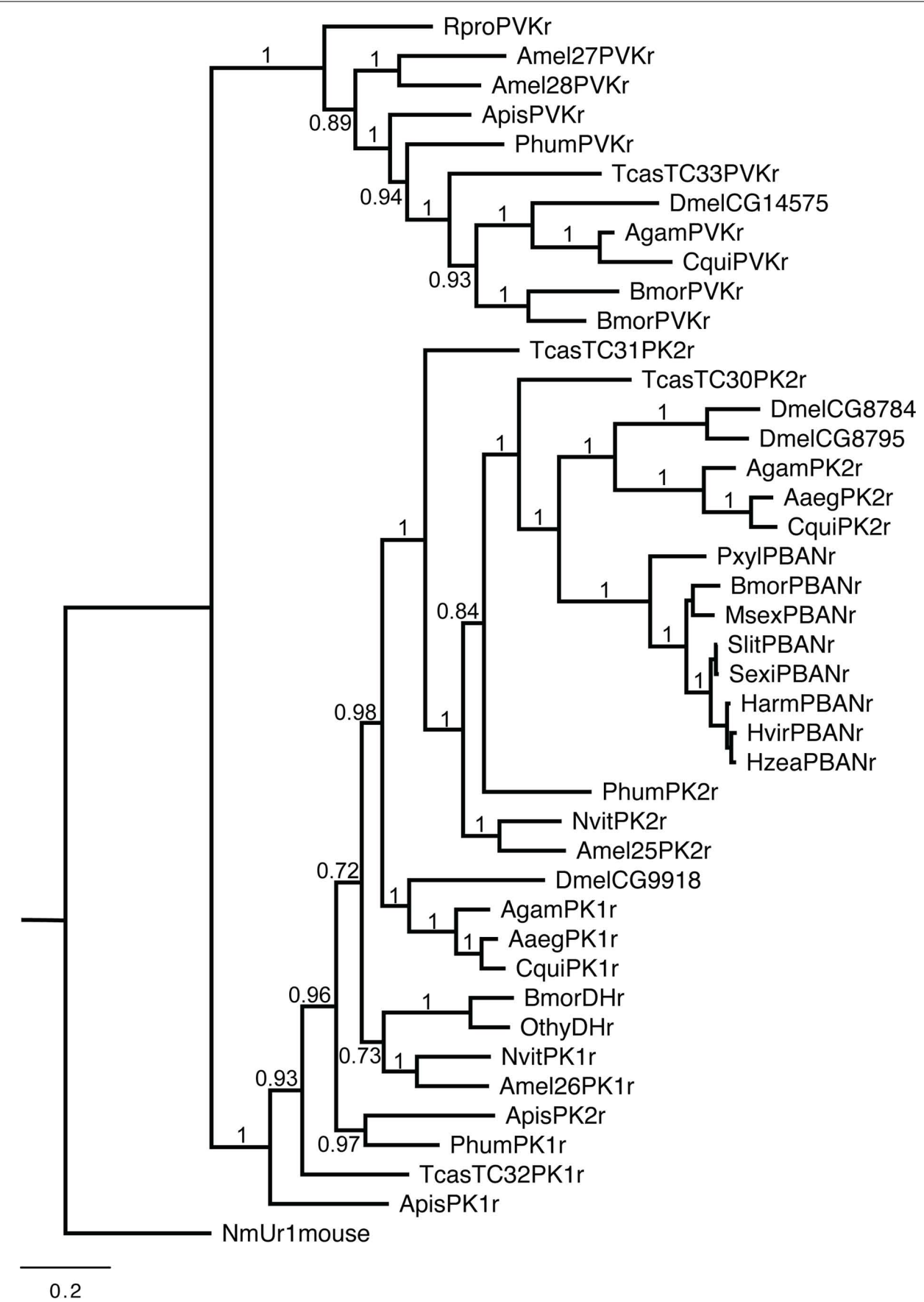

FIGURE 1 | Phylogenetic relationships of the PBAN/PK2-receptor, DH/PK1-receptor, and PVK-receptor. Species abbreviations: Aaeg, Aedes aegypti; Agam, Anopholes gambiae; Agos, Aphis gossypii; Amel, Apis mellifera; Apis, Acyrthosiphon pisum; Bmor, Bombyx mori; Cfor, Coptotermes formosanus; Cqui, Culex quinquefasciatus; Dvir, Diabrotica virgifera virgifera; Dmel, Drosophila melanogaster; Harm,
Helicoverpa armigera; Hzea, Helicoverpa zea; Hvir, Heliothis virescens; Msex, Manduca sexta; Nvit, Nasonia vitripennis; Othy, Orgyia thyellina; Phum, Pediculus humanus; Pxyl, Plutella xylostella; Rpro, Rhodnius prolixus; Sinv, Solenopsis invictus; Sexi, Spodoptera exigua; Slit, Spodoptera littoralis; Tcas, Tribolium castaneum (Jurenka and Nusawardani, 2011). could be involved in accepting the correct peptide for binding to a receptor activation site which is the ligand binding pocket located in the transmembrane domain area of the receptor. Alanine substitution mutations made in the third extracellular loop indicate that specific amino acids could be involved in peptide recognition (Choi and Jurenka, 2010). Further studies will be required to validate these models and establish how this family of receptors recognize specific peptides and activate the receptor. 


\section{PBAN MODE OF ACTION}

Pheromone biosynthesis activating neuropeptide activation of the receptor induces the influx of extracellular calcium and the subsequent increase in cytosolic calcium (Jurenka et al., 1991; Jurenka, 1996). In heliothine moths, as in all moth species examined to date, the presence of calcium in the extracellular medium is a prerequisite for PBAN action (Rafaeli, 1994; Choi et al., 2004; Choi and Jurenka, 2006) suggesting that the opening of cation channels and the concomitant influx of calcium are most likely conserved features of PBAN activation. In the absence of calcium or the presence of calcium-calmodulin inhibitors such as W7, pheromonotropic activity is abolished (Rafaeli and Gileadi, 1996a) and, conversely, the pheromonotropic effects of PBAN can be duplicated with calcium ionophores such as ionomycin, thapsigargin, and A23187 (Rafaeli and Gileadi, 1996a; Rafaeli and Jurenka, 2003).

However, unlike the signal transduction pathway determined for the silkworm B. mori, in the heliothine moths there is evidence that the increase in cystosolic calcium activates a calciumcalmodulin sensitive adenylate cyclase which in turn promotes the production of cyclic-AMP (Rafaeli and Soroker, 1989; Soroker and Rafaeli, 1995; Rafaeli and Gileadi, 1996a). Furthermore, pharmacological compounds that affect cyclic-AMP levels such as cyclicAMP analogs, isobutyl methyl xanthine (a phosphodiesterase inhibitor), and forskolin (an adenylate cyclase activator) have been shown to stimulate downstream events and thereby pheromone biosynthesis in H. armigera (Rafaeli and Soroker, 1989; Rafaeli, 1994) and H. zea (Jurenka et al., 1991). In addition, in H. armigera sodium fluoride, a G-protein activator can induce intracellular cyclic-AMP levels and subsequent downstream events leading to pheromone production, independent of the ligand PBAN (Rafaeli and Gileadi, 1996b). As an outcome of the activation of the second

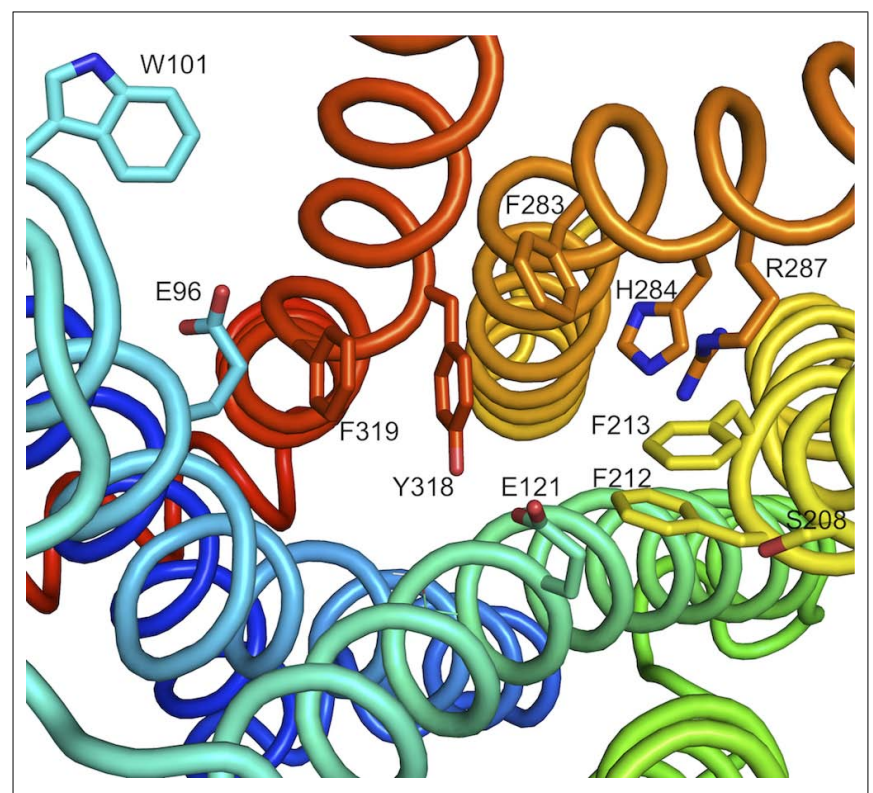

FIGURE 2 |A model of the Helicoverpa zea PBAN-receptor illustrating amino acids that could be involved in binding PBAN. Reproduced with permission from Jurenka and Nusawardani (2011). messengers, kinase, and/or phosphatase is activated, which, in their turn, stimulate fatty acid biosynthesis in the pheromone biosynthetic pathway (Figure 3).

What enzyme in the biosynthetic pathway is affected by the signal cascade brought about through PBAN binding to its receptor? Demonstration of the enzymatic key regulatory step in the biosynthesis of sex-pheromones primarily relies on following labeled precursors and intermediates into pheromone molecules in the absence and presence of PBAN. Thus, if production of a labeled pheromone component from incorporation of labeled precursor occurs in the absence of PBAN to the same extent as in its presence the labeled precursor must be acting downstream of the regulatory enzyme and therefore regulation must occur upstream. The effect of PBAN on the different steps in the biosynthetic pathway has been investigated in several Lepidopteran species including $B$. mori (Arima et al., 1991; Ozawa et al., 1993), Thaumetopoea pityocampa (Arsequell et al., 1990), S. littoralis (Martinez et al., 1990; Fabrias et al., 1994), Manduca sexta (Fang et al., 1995; Tumlinson et al., 1997), H. zea (Jurenka et al., 1991), H. armigera (Tsfadia et al., 2008), and Plodia interpunctella (Tsfadia et al., 2008). Studies

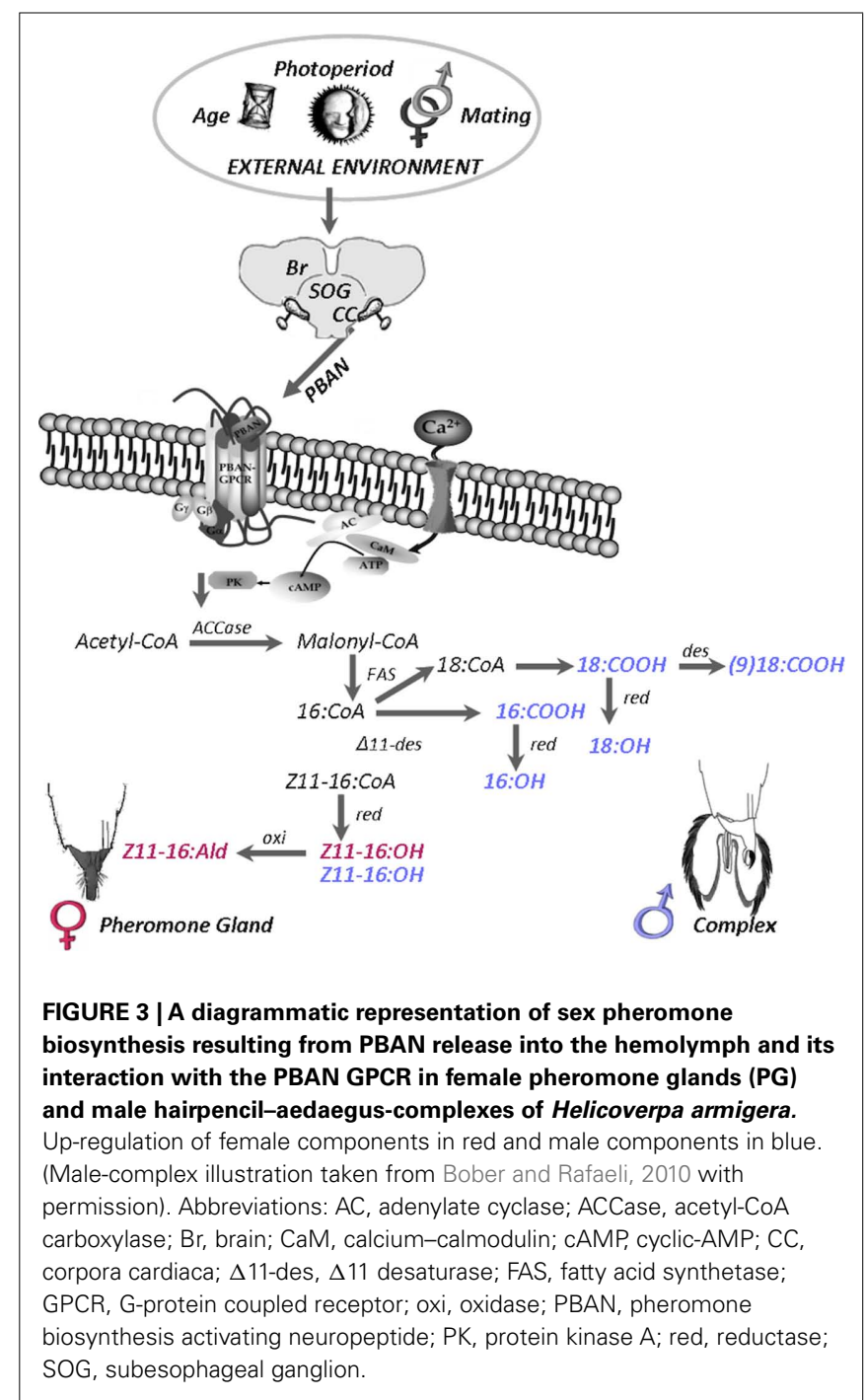


of this nature have so far indicated that PBAN does not influence desaturase activity.

Using both stable isotopes and specific enzyme inhibitors the rate limiting step of PBAN pheromone biosynthesis regulation in $H$. armigera was determined (Tsfadia et al., 2008). These studies showed that only incorporation of labeled acetate is affected by PBAN and that this incorporation can be inhibited by the acetyl coenzyme A carboxylase (ACCase) inhibitor, tralkoxydim. Levels of incorporation of labeled malonyl CoA or palmitic acid (downstream of acetate) were unaffected by the presence or absence of PBAN (Tsfadia et al., 2008). Thus, in H. armigera, the rate limiting step for PBAN control is regulation of the ACCase which catalyzes the rate limiting enzyme of fatty acid biosynthesis, prior to the action of fatty acid synthetase (Figure 3). PBAN is also thought to influence ACCase activity in Argyrotaenia velutinana (Tang et al., 1989), P. interpunctella (Tsfadia et al., 2008), and H. zea (Jurenka et al., 1991). In contrast, in B. mori, T. pityocampa, S. littoralis, and $M$. sexta PBAN stimulates a reductase that converts an acyl-CoA to an alcohol precursor (Arsequell et al., 1990; Martinez et al., 1990; Ozawa et al., 1993; Fang et al., 1995). In H. virescens a twostep regulatory role for PBAN was demonstrated (Eltahlawy et al., 2007). This two-step theory entailed a push (ACCase) and a pull (acyl-CoA) for the action of PBAN and may explain the controversial hypotheses suggested for identifying the rate limiting steps controlled by PBAN in the different moth species.

An interesting feature revealed by studies on the mode of PBAN action is that in those species in which PBAN has been shown to regulate reductase activity, cyclic-AMP has proven to be ineffective as a pheromonotropic agent whereas in those species in which PBAN regulates ACCase activity, cyclic-AMP appears to be involved as a second messenger. Moreover, it is interesting that different receptor subtypes maybe correlated with the different downstream intracellular signal cascades that are induced. It is apparent that at least two subtypes of PBAN-receptors could be located in pheromone glands: one with calcium signaling cascade including cyclic-AMP and a shorter $C$-terminal tail ( $H$. zea, $H$. armigera); the other dependent only on calcium having a longer $C$-terminal tail (B. mori). Allocating these characteristics may be too premature until more evidence becomes available as to the involvement of cyclic-AMP in the signal transduction of other PBAN-receptor subtypes. For example, PBAN induces calcium elevations by the $P$. xyllostella PBAN-receptor, which also has a short $C$-terminal tail; however cyclic-AMP levels were not analyzed in the P. xyllostella study (Lee et al., 2011).

\section{PBAN's INFLUENCE ON MALE PHEROMONAL COMPONENTS}

Male pheromone production has been studied in several insect species. Male insects often possess scent-releasing organs in the form of hairpencils, coremata, or androconial scales (Birch et al., 1990). In the Lepidoptera, studies have identified hairpencil secretions produced by several species (Chow et al., 1986; Phelan et al., 1986; Teal and Tumlinson, 1989; Heath et al., 1992; Thibout et al., 1994; Huang et al., 1996). The behavioral role of these secretions is not well understood, but most often these odors have been deemed important in courtship behavior. In general male pheromones can be considered to have many possible functions: they can act as aphrodisiacs to stimulate female receptivity during courtship
(Birch, 1974); they have been reported to induce female calling (Szentesi et al., 1975), females become immobile allowing copulation; and they have been reported to function as male-to-male inhibitory compounds, thereby minimizing male-competition (Hirai et al., 1978; Teal et al., 1984; Teal and Tumlinson, 1989; Wu et al., 1991; Huang et al., 1996). Odors released by male hairpencils are important in male acceptance by the female and may play a role in mate choice and species isolation (Hillier and Vickers, 2004; Lassance and Löfstedt, 2009). In the European corn borer, Ostrinia nubilalis, scents released during courtship by males provide critical information for female acceptance (Lassance and Löfstedt, 2009). Close-range chemical cues have also been proposed as a trait used by females to assess male quality (Eisner and Meinwald, 1995).

In species of Lepidoptera belonging to the Arctiidae and Danaidae, scent gland composition is related to host plant consumption and sequestration of compounds during the larval and adult stages (Birch and Hefetz, 1987). However, in other moth species, as in the heliothine moths, these male odors are derived from the fatty acid biosynthetic pathway, and as such are similar to the female sex-pheromone blends (Teal and Tumlinson, 1989; Huang et al., 1996). In O. nubilalis the male chemical signal is also analogous to the female signal in that structurally similar compounds are being used by both sexes and are governed by

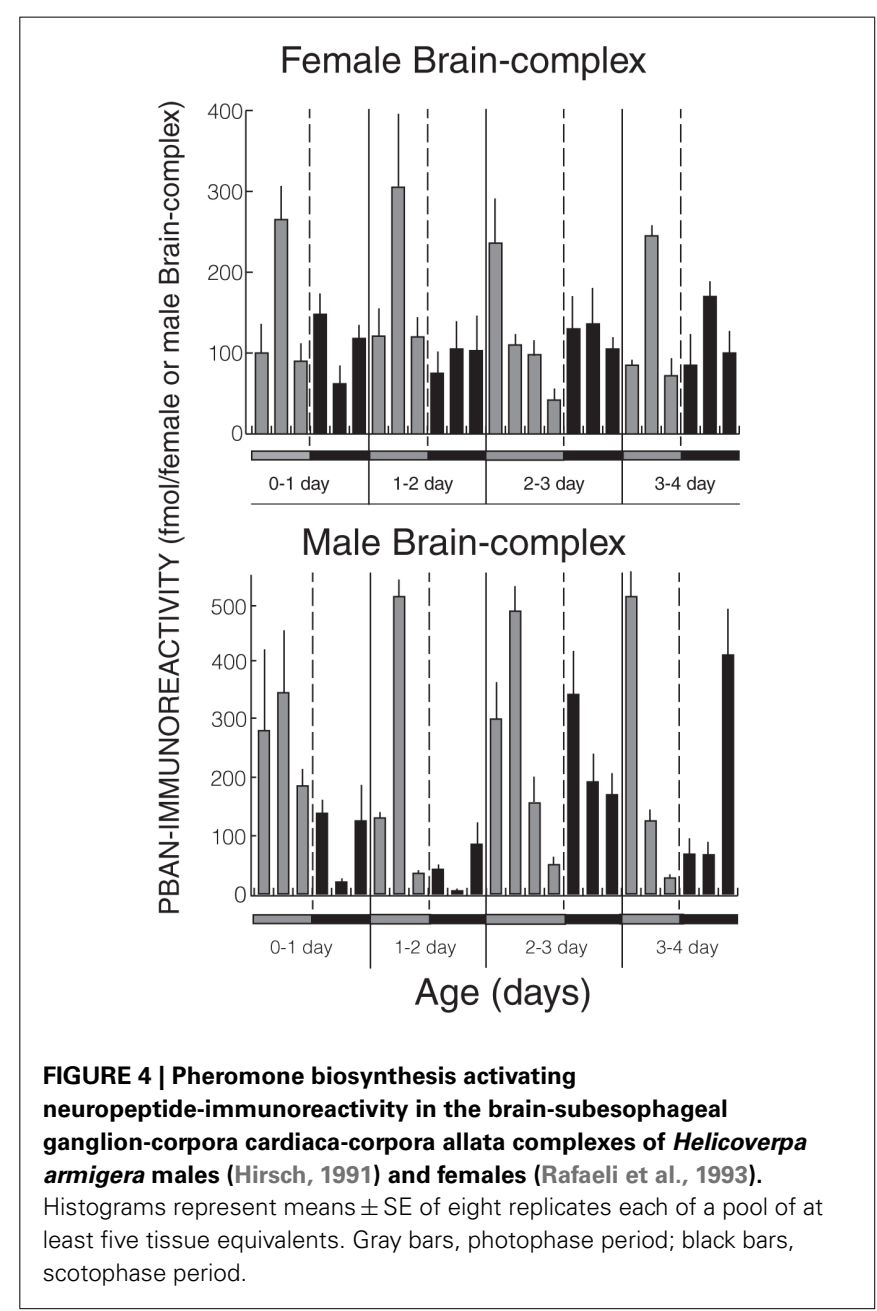


the same genes encoding biosynthetic enzymes (Lassance and Löfstedt, 2009).

Pheromone biosynthesis activating neuropeptide was originally isolated from female $H$. zea suboesophageal ganglia and its distribution in the female nervous system was studied using ELISA (Kingan et al., 1992) however the gene transcript was shown to be present in both the male and female central nervous system (Ma et al., 1998). Using an immunoassay, PBAN was also found in both female and male $H$. armigera central nervous systems and throughout the photoperiod (Figure 4; Hirsch, 1991; Rafaeli et al., 1993).

The function of PBAN in the males, however, has been a mystery since its discovery but its presence has been speculated to have other functional significances particularly in light of the pleiotropic action of PBAN and PBAN-like peptides in other insects. However, a recent temporal differential expression study of the PBAN-R revealed the presence of gene transcripts in both the male-complexes (hairpencil-aedaegus complex) and female pheromone glands of two moth species, $H$. armigera and $B$. mori (Bober et al., 2010) with levels dependent on the age of the adults and up-regulated on or just before eclosion. Whilst the presence of PBAN in males can be understood in terms of the ubiquitous characteristic of this peptide family, the presence, as well as the transcriptional regulation of its receptor in the male-complex

\section{REFERENCES}

Arima, R., Takahara, K., Kadoshima, T., Numazaki, F., Ando, T., Uchiyama, M., Nagasawa, H., Kitamura, A., and Suzuki, A. (1991). Hormonal regulation of pheromone biosynthesis in the silkworm moth, Bombyx mori (Lepidoptera: Bombycidae). Appl. Entomol. Zool. (Jpn.) 26, 137-147.

Arsequell, G., Fabrias, G., and Camps, F. (1990). Sex pheromone biosynthesis in the processionary moth Thaumetopoea pityocampa by delta-13 desaturation. Arch. Insect Biochem. Physiol. 14, 47-56.

Birch, M. C. (1974). "Aphrodisiac pheromones in insects", in Pheromones, ed. M. C. Birch (Amsterdam: North Holland), 115-134.

Birch, M. C., and Hefetz, A. (1987). Extrusible organs in male moths and their role in courtship behavior. Bull. Entomol. Soc. Am. 33, 222-229.

Birch, M. C., Poppy, G. M., and Baker, T. C. (1990). Scents and eversible scent structures of male moths. Annu. Rev. Entomol. 35, 25-58.

Blackburn, M. B., Kingan, T. G., Raina, A. K., and Ma, M. C. (1992). Colocalization and differential expression of PBAN- and FMRF-like immunoreactivity in the subesophageal ganglion of Helicoverpa zea (Lepidoptera: Noctuidae) during development. Arch. Insect Biochem. Physiol. 21, 225-238.
Bober, R., Azrielli, A., and Rafaeli, A. (2010). Developmental regulation of the pheromone biosynthesis activating neuropeptide-receptor (PBAN$\mathrm{R})$ : re-evaluating the role of juvenile hormone. Insect Mol. Biol. 19, 77-86.

Bober, R., and Rafaeli, A. (2010). Genesilencing reveals the functional significance of pheromone biosynthesis activating neuropeptide receptor (PBAN-R) in a male moth. Proc. Natl. Acad. Sci. U.S.A. 107, 16858-16862.

Cheng, Y., Luo, L., Jiang, X., Zhang, L., and Niu, C. (2010). Expression of pheromone biosynthesis activating neuropeptide and its receptor (PBANR) mRNA in adult female Spodoptera exigua (Lepidoptera: Noctuidae). Arch. Insect Biochem. Physiol. 75, 13-27.

Choi, M.-Y., Fuerst, E.-J., Rafaeli, A., and Jurenka, R. (2003). Identification of a $G$ protein-coupled receptor for pheromone biosynthesis activating neuropeptide from pheromone glands of the moth, Helicoverpa zea. Proc. Natl. Acad. Sci. U.S.A. 100, 9721-9726.

Choi, M.-Y., Fuerst, E.-J., Rafaeli, A., and Jurenka, R. (2007). Role of extracellular domains insects using chimera receptors. Insect Biochem. Mol. Biol. 37, 296-306.

Choi, M.-Y., Lee, J. M., Han, K. S., and Boo, K. S. (2004). Identification in PBAN/Pyrokinin GPCRs from

called for a re-examination of a possible function for PBAN and its receptor in this tissue.

As discussed above, and, since fatty acid-derived pheromonal compounds were identified in male-complexes of several moth species including heliothine moths, we aimed to determine whether PBAN plays a role in the regulation of the biosynthesis of these compounds in male $H$. armigera. We utilized both physiological bioassays and RNA interference (RNAi) technology to identify several male pheromone components that are responsive to PBAN stimulation and to photoperiod, and are also significantly affected by silencing of the PBAN-R (Bober and Rafaeli, 2010). We hypothesized that these components are key in the chemical communication between females and males during copulation (Figure 4). It remains to be demonstrated that those PBAN upregulated male produced compounds are indeed responsible for a successful mating encounter by either arresting females for copulation, increasing their receptivity, or deterring co-specific males from competing.

\section{ACKNOWLEDGMENTS}

Research originating from the authors' laboratories was supported by Research Grant No. IS-4163-08C from BARD, The United States - Israel Binational Agricultural Research and Development Fund.

of a new member of PBAN family and immunoreactivity in the central nervous system from Adoxophyes sp. (Lepidoptera: Tortricidae). Insect Biochem. Mol. Biol. 34, 927-935.

Choi, M.-Y., and Jurenka, R. A. (2006). Role of extracellular calcium and calcium channel activated by a $G$ protein-coupled receptor regulating pheromone production in Helicoverpa zea (Lepidoptera: Noctuidae). Ann. Entomol. Soc. Am. 99, 905-909.

Choi, M.-Y., and Jurenka, R. A. (2010). Site-directed mutagenesis and PBAN activation of the Helicoverpa zea PBAN-receptor. FEBS Lett. 584, 1212-1216.

Chow, Y. S., Lin, Y. M., and Teng, H. J. (1986). "Morphological and biological evidence for the presence of a male sex pherome of the diamondback moth," in Diamondback Moth Management: Proceedings of the First International Workshop, eds N. S. Talekar and T. D. Griggs (Shanhua: Asian Vegetable Research and Development Center), 103-108.

Davis, M. B., Vakharia, V. N., Henry, J., Kempe, T. G., and Raina, A. K. (1992). Molecular cloning of the pheromone biosynthesis-activating neuropeptide in Helicoverpa zea. Proc. Natl. Acad. Sci. U.S.A. 89, 142-146.

Eisner, T., and Meinwald, J. (1995). The chemistry of sexual selection. Proc. Natl. Acad. Sci. U.S.A. 92, 50-55.
Eltahlawy, H., Buckner, J. S., and Foster, S. P. (2007). Evidence for two-step regulation of pheromone biosynthesis by the pheromone biosynthesis-activating neuropeptide in the moth Heliothis virescens. Arch. Insect Biochem. Physiol. 64, 120-130.

Fabrias, G., Marco, M. P., and Camps, F. (1994). Effect of the pheromone biosynthesis activating neuropeptide on sex pheromone biosynthesis in Spodoptera littoralis isolated glands. Arch. Insect Biochem. Physiol. 27, 77-87.

Fang, N., Teal, P. E. A., and Tumlinson, J. H. (1995). PBAN regulation of pheromone biosynthesis in female tobacco hornworm moths, Manduca sexta (L.). Arch. Insect Biochem. Physiol. 29, 35-44.

Heath, R. R., Landolt, P. J. Dueben, B. D. Murphy, R. E., and Schneider, R. E. (1992). Identification of male cabbage looper sex pheromone attractive to females. J. Chem. Ecol. 18, 441-453.

Hewes, R. S., and Taghert, P. H. (2001). Neuropeptides and neuropeptide receptors in the Drosophila melanogaster genome. Genome Res. 11, 1126-1142.

Hillier, N. K., and Vickers, N. J. (2004). The role of Heliothine hair pencil compounds in female Heliothis virescens (Lepidoptera: Noctuidae) behavior and mate acceptance. Chem. Senses 29, 499-511. 
Hirai, K., Shorey, H. H., and Gaston, L. K. (1978). Competition among courting male moths: male-to-male inhibitory pheromone. Science 202, 844-845.

Hirsch, J. (1991). Distribution and Mode of Action of Pheromone Biosynthesis Activating Neuropeptide (PBAN) in the Moth Helicoverpa (Heliothis) Armigera. M.Sc. thesis, The Hebrew University of Jerusalem, Faculty of Agriculture, Rehovot.

Holman, G. M., Cook, B. J., and Nachman, R. J. (1986). Isolation, primary structure and synthesis of a blocked neuropeptide isolated from the cockroach, Leucophaea maderae. Comp. Biochem. Physiol. 85C, 219-224.

Homma, T., Watanabe, K., Tsurumaru, S., Kataoka, H., Imai, K., Kamba, M., Niimi, T., Yamashita, O., and Yaginuma, T. (2006). G protein-coupled receptor for diapause hormone, an inducer of Bombyx embryonic diapause. Biochem. Biophys. Res. Commun. 344, 386-393.

Huang, Y. P., Xu, S. F. Tang, X. H. Zhao, Z. W., and Du, J. W. (1996). Male orientation inhibitor of cotton bollworm: identification of compounds produced by male hairpencil glands. Entomol. Sin. 3, 172-182.

Hull, J. J., Ohnishi, A., Moto, K. I., Kawasaki, Y., Kurata, R., Suzuki, M. G., and Matsumoto, S. (2004). Cloning and characterization of the pheromone biosynthesis activating neuropeptide receptor from the silkmoth, Bombyx mori: significance of the carboxyl terminus in receptor internalization. J. Biol. Chem. 279, 51500-51507.

Imai, K., Konno, T., Nakazawa, Y., Komiya, T., Isobe, M., Koga, K., Goto, T., Yaginuma, T., Sakakibara, K., Hasegawa, K., and Yamashita, O. (1991). Isolation and structure of diapause hormone of the silkworm, Bombyx mori. Proc. Jpn. Acad. 67, 98-101.

Iversen, A., Cazzamali, G., Williamson, M., Hauser, F., and Grimmelikhuijzen, C. J. P. (2002). Molecular cloning and functional expression of a Drosophila receptor for the neuropeptides capa-1 and -2 . Biochem. Biophys. Res. Commun. 299, 628-633.

Jurenka, R., and Nusawardani, T. (2011). The pyrokinin/pheromone biosynthesis-activating neuropeptide (PBAN) family of peptides and their receptors in Insecta: evolutionary trace indicates potential receptor ligand-binding domains. Insect Mol. Biol. 20, 323-334.

Jurenka, R. A. (1996). Signal transduction in the stimulation of sex pheromone biosynthesis in moths. Arch. Insect Biochem. Physiol. 33, 245-258.

Jurenka, R. A., Jacquin, E., and Roelofs, W. L. (1991). Control of the pheromone biosynthetic pathway in Helicoverpa zea by the pheromone biosynthesis activating neuropeptide. Arch. Insect Biochem. Physiol. 17, 81-91.

Kean, L., Cazenave, W., Costes, L., Broderick, K. E., Graham, S., Pollock, V. P., Davies, S. A., Veenstra, J. A., and Dow, J. A. T. (2002). Two nitridergic peptides are encoded by the gene capability in Drosophila melanogaster. Am. J. Physiol. Regul. Integr. Comp. Physiol. 282, R1297R1307.

Kim, Y.-J., Nachman, R. J., Aimanova, K., Gill, S., and Adams, M. E. (2008). The pheromone biosynthesis activating neuropeptide (PBAN) receptor of Heliothis virescens: identification, functional expression, and structure-activity relationships of ligand analogs. Peptides 29, 268-275.

Kingan, T. G., Blackburn, M. B., and Raina, A. K. (1992). The distribution of pheromone biosynthesisactivating neuropeptide (PBAN) immunoreactivity in the central nervous system of the corn earworm moth, Helicoverpa zea. Cell Tissue Res. 270, 229-240.

Lassance, J.-M., and Löfstedt, C. (2009). Concerted evolution of male and female display traits in the European corn borer, Ostrinia nubilalis. BMC Biol. 7, 10. doi:10.1186/1741-7007-7-10

Lee, D.-W., Shrestha, S., Kim, A. Y., Park, S. J., Yang, C. Y., Kim, Y., and Koh, Y. H. (2011). RNA interference of pheromone biosynthesisactivating neuropeptide receptor suppresses mating behavior by inhibiting sex pheromone production in Plutella xylostella (L.). Insect Biochem. Mol. Biol. 41, 236-243.

Ma, P. W. K., Knipple, D. C., and Roelofs, W. L. (1994). Structural organization of the Helicoverpa zea gene encoding the precursor protein for pheromone biosynthesis-activating neuropeptide and other neuropeptides. Proc. Natl. Acad. Sci. U.S.A. 91, 6506-6510.

Ma, P. W. K., Knipple, D. C., and Roelofs, W. L. (1998). Expression of a gene that encodes multiple neuropeptides in the central nervous system of corn earworm, Helicoverpa zea. Insect Biochem. Mol. Biol. 28, 373-385.

Ma, P. W. K., Roelofs, W. L., and Jurenka, R. A. (1996). Characterization of
PBAN and PBAN-encoding gene neuropeptides in the central nervous system of the corn earworm moth, Helicoverpa zea. J. Insect Physiol. 42, 257-266.

Martinez, T., Gabrias, G., and Camps, F. (1990). Sex pheromone biosynthetic pathway in Spodoptera littoralis and its activity by a neurohormone. $J$. Biol. Chem. 256, 1381-1387.

Matsumoto, S., Kitamura, A., Nagasawa, H., Kataoka, H., Orikasa, C., Mitsui, T., and Suzuki, A. (1990). Functional diversity of a neurohormone produced by the suboesophageal ganglion: molecular identity of melanization and reddish colouration hormone and pheromone biosynthesis activating neuropeptide. J. Insect Physiol. 36, 427-432.

Olsen, S. S., Cazzamali, G., Williamson, M., Grimmelikhuijzen, C. J. P., and Hauser, F. (2007). Identification of one capa and two pyrokinin receptors from the malaria mosquito Anopheles gambiae. Biochem. Biophys. Res. Commun. 362, 245-251.

Ozawa, R. A., Ando, T., Nagasawa, H., Kataoka, H., and Suzuki, A. (1993). Reduction of the acyl group: the critical step in bombykol biosynthesis that is regulated in vitro by the neuropeptide hormone in the pheromone gland of Bombyx mori. Biosci. Biotechnol. Biochem. 57, 2144-2147.

Park, Y., Kim, Y.-J., and Adams, M. E. (2002). Identification of G proteincoupled receptors for Drosophila PRXamide peptides, CCAP, corazonin, and $\mathrm{AKH}$ supports a theory of ligand-receptor coevolution. Proc. Natl. Acad. Sci. U.S.A. 99, 11423-11428.

Phelan, P. L., Silk, P. J., Northcott, C. J., Tan, S. H., and Baker, T. C. (1986). Chemical identification and behavioral characterization of male wing pheromone of Ephesia elutella (Pyralidae). J. Chem. Ecol. 12, 135-146.

Rafaeli, A. (1994). Pheromonotropic stimulation of moth pheromone gland cultures in vitro. Arch. Insect Biochem. Physiol. 25, 287-299.

Rafaeli, A., Bober, R., Becker, L., Choi, M. Y., Fuerst, E. J., and Jurenka, R. (2007). Spatial distribution and differential expression of the PBAN receptor in tissues of adult Helicoverpa spp. (Lepidoptera: Noctuidae). Insect Mol. Biol. 16, 287-293.

Rafaeli, A., and Gileadi, C. (1996a). Down regulation of pheromone biosynthesis: cellular mechanisms of pheromonostatic responses. Insect Biochem. Mol. Biol. 26, 797-807.
Rafaeli, A., and Gileadi, C. (1996b). "Multi-signal transduction of moth pheromone biosynthesisactivating neuropeptide (PBAN) and its modulation: involvement of G-proteins?", in The Peptidergic Neuron, eds B. Kirsch and R. Mentlein (Basel: Birkhauser), 239-244.

Rafaeli, A., and Jurenka, R. A. (2003). "PBAN regulation of pheromone biosynthesis in female moths," in Pheromone Biochemistry and Molecular Biology, eds G. J. Blomquist and R. Vogt (San Diego: Academic Press), 107-136.

Rafaeli, A., and Soroker, V. (1989). Cyclic-AMP mediation of the hormonal stimulation of $\left[{ }^{14} \mathrm{C}\right]$-acetate incorporation by Heliothis armigera pheromone glands in vitro. Mol. Cell. Endocrinol. 65, 43-48.

Rafaeli, A., Soroker, V., Hirsch, J., Kamensky, B., and Raina, A. K. (1993). Influence of photoperiod and age on the competence of pheromone glands and on the distribution of immunoreactive PBAN in Helicoverpa spp. Arch. Insect Biochem. Physiol. 22, 169-180.

Rafaeli, A., Zakharova, T., Lapsker, Z., and Jurenka, R. A. (2003). The identification of an age- and femalespecific putative PBAN membranereceptor protein in pheromone glands of Helicoverpa armigera: possible up-regulation by juvenile hormone. Insect Biochem. Mol. Biol. 33, 371-380.

Raina, A., and Kempe, T. (1990). A pentapeptide of the Cterminal sequence of PBAN with pheromonotropic activity. Insect Biochem. 20, 849-851.

Raina, A. K., Jaffe, H., Kempe, T. G., Keim, P., Blacher, R. W., Fales, H. M., Riley, C. T., Klun, J. A., Ridgway, R. L., and Hayes, D. K. (1989). Identification of a neuropeptide hormone that regulates sex pheromone production in female moths. Science 244, 796-798.

Raina, A. K., Jaffe, H., Klun, J. A., Ridgway, R. L., and Hayes, D. K. (1987). Characteristics of a neurohormone that controls sex pheromone production in Heliothis zea. J. Insect Physiol. 33, 809-814.

Raina, A. K., and Kempe, T. G. (1992). Structure activity studies of PBAN of Helicoverpa zea (Lepidoptera: Noctuidae). Insect Biochem. Mol. Biol.22, 221-225.

Soroker, V., and Rafaeli, A. (1995). Multi-signal transduction of the pheromonotropic response by pheromone gland incubations of Helicoverpa armigera. Insect Biochem. Mol. Biol. 25, 1-9. 
Stern, P. S., Yu, L., Choi, M.-Y., Jurenka, R. A., Becker, L., and Rafaeli, A. (2007). Molecular modeling of the binding of pheromone biosynthesis activating neuropeptide to its receptor. J. Insect Physiol. 53, 803-818.

Sun, J.-S., Zhang, T.-Y., Zhang, Q.-R., and $\mathrm{Xu}, \mathrm{W} . \mathrm{-H}$. (2003). Effect of the brain and suboesophageal ganglion on pupal development in Helicoverpa armigera through regulation of FXPRLamide neuropeptides. Regul. Pept. 116, 163-171.

Szentesi, A., Toth, M., and Dodrovolsky, A. (1975). Evidence and preliminary investigation on a male aphrodisiac and a female sex pheromone in Mamestra brassicae (L.) Acta Phytopathol. Hung. 10, 425-429.

Tang, J. D., Charlton, R. E., Jurenka, R. A., Wolf, W. A., Phelan, P. L., Streng, L., and Roelofs, W. L. (1989). Regulation of pheromone biosynthesis by a brain hormone in two moth species. Proc. Natl. Acad. Sci. U.S.A. 86, 1806-1810.

Teal, P. E. A., and Tumlinson, J. H. (1989). Isolation, identification and biosynthesis of compounds produced by male hairpencil glands of Heliothis virescens (F.) (Lepidoptera: Lepidoptera). J. Chem. Ecol. 15, 413-427.

Teal, P. E. A., Tumlinson, J. H., Mclaughlin, F. R., Heath, R. R., and Rush, R. A. (1984). (Z)-11-hexadecanol: a behavioral modifying chemical present in the pheromone gland of female Heliothis zea (Lepidoptera: Noctuidae). Can. Entomol. 116, 777-779.

Thibout, E., Ferary, S., and Auger, J. (1994). Nature and role of sexual pheromones emitted by males of Ascrolepiopsis assectella (Lep.). J. Chem. Ecol. 20, 1571-1581.

Tsfadia, O., Azrielli, A., Falach, L., Zada, A., Roelofs, W. L., and Rafaeli, A. (2008). Pheromone biosynthetic pathways: PBAN-regulated rate-limiting steps and differential expression of desaturase genes in moth species. Insect Biochem. Mol. Biol. 38, 552-567

Tumlinson, J. H., Fang, N., and Teal, P. E. A. (1997). "The effect of PBAN on conversion of fatty acyls to pheromone aldehydes in female," in Insect Pheromone Research: New
Directions, eds R. T. Cardé and A. K. Minks (New York: Chapman and Hall), 54-55.

Wu, W. Q., Tang, X. H., Xu, S. F., and Du, J. W. (1991). The diel rhythm of calling behavior and sex pheromone production of Helicoverpa armigera (Hubner) (Lepidoptera: Noctuidae). Contributions from Shanghai Institute of Entomology 10, 57-62.

Zdarek, J., Nachman, R. J., and Hayes, T. K. (1997). Insect neuropeptides of the pyrokinin/PBAN family accelerate pupariation in the fleshfly (Sarcophaga bullata) larvae. Ann. N. Y. Acad. Sci. 814, 67-72.

Zhang, T.-Y., Sun, J.-S., Zhang, Q.-R., $\mathrm{Xu}, \mathrm{J}$., Jiang, R.-J., and $\mathrm{Xu}, \mathrm{W}$.H. (2004). The diapause hormonepheromone biosynthesis activating neuropeptide gene of Helicoverpa armigera encodes multiple peptides that break, rather than induce, diapause. J. Insect Physiol. 50, 547-554.

Zheng, L., Lytle, C., Njauw, C.-N., Altstein, M., and Martins-Green, M. (2007). Cloning and characterization of the pheromone biosynthesis activating neuropeptide receptor gene in Spodoptera littoralis larvae. Gene 393, 20-30.

Conflict of Interest Statement: The authors declare that the research was conducted in the absence of any commercial or financial relationships that could be construed as a potential conflict of interest.

Received: 24 June 2011; accepted: 15 September 2011; published online: 10 October 2011.

Citation: Jurenka $R$ and Rafaeli $A$ (2011) Regulatory role of PBAN in sex pheromone biosynthesis of heliothine moths. Front. Endocrin. 2:46. doi: 10.3389/fendo.2011.00046

This article was submitted to Frontiers in Experimental Endocrinology, a specialty of Frontiers in Endocrinology.

Copyright (C) 2011 Jurenka and Rafaeli. This is an open-access article subject to a non-exclusive license between the authors and Frontiers Media SA, which permits use, distribution and reproduction in other forums, provided the original authors and source are credited and other Frontiers conditions are complied with. 